\title{
Pharmacognostic and Phytochemical Characteristics of the Fruits of Bunium persicum (Boiss.) B. Fedtsch, Growing Wild in Kashmir Valley, India
}

Riehana Gani, Zulfiqar Ali Bhat*, Mudasir Ahmad Dar, Mohammad Akbar Dar, Junaid ul Yousuf Rather

Department of Pharmaceutical Sciences, University of Kashmir, Hazratbal, Srinagar, Jammu and Kashmir, INDIA.

\begin{abstract}
Introduction: Bunium persicum (Boiss.) B. Fedtsch belongs to family Apiaceae of genus Bunium, which is comprised of about 166 species and is widely distributed in Kashmir valley. It is used medicinally in dyspepsia and diarrhea, digestive and urinay tract infections, chronic gastiritis, colitis, anticonvulsant, antiasthma and diuretic. Objectives: The current study deals with Pharmacognostic parameters of the fruits of Bunium persicum (Boiss.) B. Fedtsch. Materials and Methods: The fruits of Bunium persicum (Boiss.) B. Fedtsch was collected, shade dried for about 2 weeks and powdered and the powered fruit part of plant material was evaluated for Pharmacognostic parameters by standard methods. The hydroalcholic extract of Bunium persicum was subjected to preliminary phytochemical screening for the presence of various Phytoconstituents. The microscopy of the fruits of Bunium persicum (Boiss.) B. Fedtsch reveals the presence of Part of a group of sclereids from the mesocarp, thicker-walled sclereids with adjacent thin walled parenchyma, Fragment of vitta, Thin-walled fibre and Calcium-oxalate crystals. Results: Proximate analysis of the fruits of Bunium persicum (Boiss.) B. Fedtsch showed that the dried fruit powder has $34.0 \%$ Total ash value, $29.0 \%$ Acid insoluble ash value, $9.5 \%$
\end{abstract}

Sulphated ash value. Loss on drying was found to be $6.2 \%$. The hydroalcholic extract of Bunium persicum was found to contain various phytoconstituents. Fluorescence analysis of the fruit powder showed the behavour, when treated with different chemical reagents. Conclusion: The current study displayed the microscopical characters, the preliminary phytochemical screening and the proximate analysis of the fruits of Bunium persicum (Boiss.) B. Fedtsch. Data composed from such studies can be used as standard in the quality control of this plant as a herbal medicine for treatment of various diseases.

Key words: Bunium persicum, Proximate Analysis, Fluorescence Analysis, Phytochemical Screening, Microscopical Characters.

\section{Correspondence}

Prof. Zulfiqar Ali Bhat

Prof. and Head, Department of Pharmaceutical Sciences, University of Kashmir, Hazratbal, Srinagar-190006, Jammu and Kashmir, INDIA.

Phone no: +91 7006771995

Email: rehanagani35@rediffmail.com

DOI: 10.5530/ijpi.2020.1.3

\section{INTRODUCTION}

The genus Bunium belongs to a family Apiaceae, which comprised about 166 species. Bunium persicum (Boiss.) B. Fedtsch is one of the species of genus Bunium, which is economically and medicinally important. Bunium persicum (Boiss.) B. Fedtsch is widely distributed in the warm climate such as Central and Western Asia including Iran, Syria, Pakistan, Afghanistan, Tajikistan, North India (Kashmir and Pamir), China and some parts of North Africa, Europe and South America. ${ }^{1-3}$ In Kashmir valley it is found in Gurez, Harwan Dara, Baramulla, Chrarisharief, Wasturwan Tral and Khrew. ${ }^{4}$ Bunium persicum (Boiss.) B. Fedtsch is known with varous names across the world like Black zire, Great pignut, Persian cumin, Black caraway, Kala zeera, Shahi zeera, Jira, Wild cumin, Wild caraway and Zire kuhi. ${ }^{4,5}$ It is a perennial, aromatic plant bearing small pink or white flowers with readily symmetrical small sepals, petals and stamens (Each five in number) and are present in compact umbels. This plant can attain a height of about $60 \mathrm{~cm}$ and $25 \mathrm{~cm}$ wide. The leaves are freely, pinnate (2-3), finely dissected and filiform. The fruit of $\mathrm{Bu}$ nium persicum is slender, dark brownish in colour and crescent shape. The stem is often hollow in the internodal region with secretory canals containing ethereal oils and resins. ${ }^{6}$ The major bioactive constituents that have been identified in Bunium persicum are cuminaldehyde, pmentha-1,4-dien-7-al, gamma- terpinene, beta-pinene, alpha -thujene and myrecene. ${ }^{7}$ The fruits of Bunium persicum (Boiss.) B. Fedtsch are widely used as condiment, stimulant and carminative. Therapeutically, the fruits of Bunium persicum are used to treat dyspepsia and diarrhea, digestive and urinay tract infections, chronic gastiritis, colitis, kidney stones, chronic cholangitis, jaundice, swelling and jaundice. It is also used as flow increaser of breast milk, antidiabetic, antispasmodic, antiasthma, antiepileptic, diuretic and anticonvulsant. ${ }^{2}$ Besides, it also shows good antioxidant and anti-inflammatory, free radical scavenging, antimicrobial and antiparasitic activities are reported for fruits of Bunium persicum. ${ }^{5,8}$ Despite, of the medicinal importance of Bunium persicum there is deficiency of information available on the Pharmacognostic parameters for identification and standardization of this species in whole as well as in powder form. The current study is schemed at the standardization and monograph development and to evaluate the Macroscopical, microscopical and Pharmacognostic parameters and phytochemical screening of the fruits of Bunium persicum (Boiss.) B. Fedtsch.

\section{MATERIALS AND METHODS}

The fruits of Bunium persicum (Boiss.) B. Fedtsch was collected from the Gurez-Bandipora, Jammu and Kashmir, India. This plant was identified and authenticated by Akhtar H. Malik, Curator Centre for Biodiversity and Taxonomy (CBT) Department of Botany, University of Kashmir under specimen voucher no. $2710 \mathrm{KASH}$. A sample specimen of collected material was deposited in herbarium for future references. 


\section{Reagents}

The reagents used for this work were all of analytical grade obtained from Central Drug House (P) LTD., Bombay, India.

\section{Macroscopical and Microscopical Evaluation}

Macroscopical and Microscopical evaluation of the fruits of Bunium persicum (Boiss.) B. Fedtsch were studied according to the methods described in Trease and Evans Pharmacognosy. ${ }^{9,10}$ The Macroscopical and Microscopical evaluation of Bunium persicum was taken to prevent adulteration and mistaken in selection procedures of raw medicinal material from genus Bunium.

\section{Preparation of Extracts}

The fresh air-dried ripe fruits of Bunium persicum (Boiss.) B. Fedtsch was powdered and the powdered sample of plant material was then subjected to hydroalcoholic extraction by using soxhlet extractor for $72 \mathrm{hr}$ the hydroalcoholic extract obtained was filtered through whatman filter paper and concentrated under reduced pressure using rotary vacuum evaporator. The Hydroalcholic extract was then dried and transferred in a closed air tight container for further use.

\section{Proximate Analysis}

On the powdered fruits of Bunium persicum, Proximate Analysis was performed for the evaluation of various physicochemical parameters such as extractive value (hot and cold),${ }^{11}$ loss on drying ${ }^{12}$ total ash value, acid insoluble ash value, sulphated ash value ${ }^{13}$ and $\mathrm{PH}$ determination (1\% and $10 \%)$ solution of drug. ${ }^{14}$ Fluorescence analysis study of powdered drug material was carried out by treating with different chemical reagents to detect the colour change under UV at $254 \mathrm{~nm}$ and $366 \mathrm{~nm}$ and under visible light. ${ }^{15,16}$ The preliminary phytochemical screening was carried out on the hydroalcholic extract of the fruits of Bunium persicum to determine the presence of various phytoconstituents. ${ }^{17,18}$

\section{RESULTS}

\section{Macroscopical Evaluation}

$\begin{array}{ll}\text { Colour: } & \text { Black-brownish } \\ \text { Size: } & 4.7 \mathrm{~mm} \text { long and } 1.6 \mathrm{~mm} \text { wide } \\ \text { Taste: } & \text { Astringent } \\ \text { Odour: } & \text { Aaromatic } \\ \text { Shape: } & \text { Slenderical. }\end{array}$

\section{Powder Microscopy of the Fruits of Bunium persicum}

When the powdered fruit part of Bunium persicum was examined under microscope, it showed (i) The presence of the sclereids of the mesocarp which occur in large groups and often associated with thicker-walled sclereids with adjacent thin walled parenchyma (ii) It also showed presence of fragment of a vittae which is composed of thin- walled cells - polygonal in shape (iii) Further the powdered fruit part under microscope reveals the presence of thin-walled fibre and (iv) Endosperm containing calcium oxalate crystals. The various characters observed are given in Figure 1.

\section{Proximate Analysis and Phytochemical Screening of Bunium persicum}

For the evaluation of Pharmacognostic parameters of the fruits of $\mathrm{Bu}$ nium persicum, the proximate analysis was used as shown in (Table 1). The phytochemical screening of hydroalcholic extract of the fruits of $\mathrm{Bu}$ nium persicum showing presence of various Phytoconstituents are shown in (Table 2). The fluorescence analysis of powdered drug treatment with

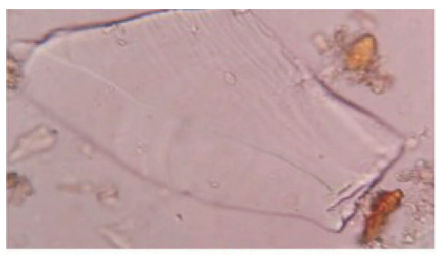

(a) Calcium oxalate crystals

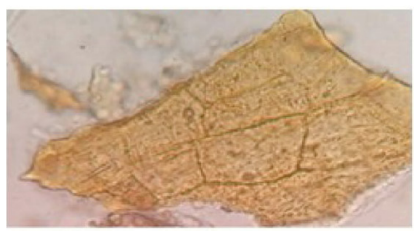

(C) Fragments of vitta

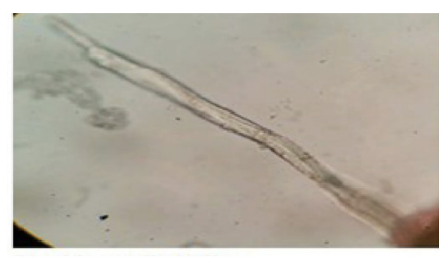

(b) Thin- walled Fibre

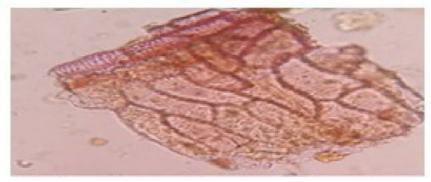

(d) Part of group of Sclereids from the Mesocarp Associated with Thicker- Walled Sclereids with

Adjacent thin Walled Parenchyma
Figure 1: Shows the Observation of Various Powder Characters of Fruits of Bunium persicum with (a) Calcium Oxalate Crystal (b) Thin- Walled Fiber (c) Fragments of Vitta and (d) Part of Sclereids from the Mesocarp Associated with Thicker-Walled Sclereids with Adjacent thin Walled Parenchyma.

Table 1: Physicochemical Analysis and Extractive Value of the Fruits of Bunium persicum.

\begin{tabular}{|c|c|}
\hline Physicochemical parameters & Results \\
\hline Total ash value (\%w/w) & 34.0 \\
\hline Acid insoluble ash value $(\% \mathrm{w} / \mathrm{w})$ & 29.0 \\
\hline Sulphated ash value (\%w/w) & 9.5 \\
\hline Loss on drying $(\% \mathrm{w} / \mathrm{w})$ & 6.2 \\
\hline Swelling index (\%w/w) & 1 \\
\hline Foreign matter $(\% \mathrm{w} / \mathrm{w})$ & 0.016 \\
\hline Foaming index & Less than 100 \\
\hline $\mathrm{PH}$ of $1 \%$ soution & 6.5 \\
\hline $\mathrm{PH}$ of $10 \%$ solution & 6.1 \\
\hline Extractive values (\%w/w) & $\begin{array}{c}\text { Cold extractive value Hot extractive } \\
\text { value }\end{array}$ \\
\hline Ethanolic & 17.5 \\
\hline Aqueous & 15.6 \\
\hline
\end{tabular}

different reagents was studied under visible light and under UV light as shown in (Table 3).

\section{DISCUSSION}

Genus Bunium has been largely used as medicinal agent, a number of researches revealed that the presence of medicinal substances in the fruits of Bunium persicum. This study revealed the characteristics of macroscopy, microscopy and Pharmacognostic parameters from the fruits of Bunium persicum. This data is expected to be a reference for the selection of raw material for the production of crude extract from the fruits of Bunium persicum. According to World Health Organization guidelines, the macroscopic and microscopic characters are the initial steps in the determination of degree of purity and identification of such materials. The current Macroscopical and microscopical observations of the fruits of Bunium persicum, thus provides the useful information for quality control parameters for the crude drugs. The ash value was used to detect the presence of foreign matters in the sample such as sand and soil. The extractive value was used to determine the amount of active constituents. Loss on drying determine the amount of moisture as well as volatile content present in a drug. $\mathrm{PH}$ determination showed the concentration 
Table 2: Phytochemical Screening of Hydroalcoholic Extract of the Fruits of Bunium persicum.

\begin{tabular}{|c|c|c|}
\hline Tests & Inference & $\begin{array}{c}\text { Hydroalcholic } \\
\text { extract }\end{array}$ \\
\hline \multicolumn{3}{|l|}{ Carbohydrates } \\
\hline Molish's test & Violet ring & ++ \\
\hline Fehling's test & Brick red ppt & ++ \\
\hline Barfoed's test & Brick red ppt & ++ \\
\hline \multicolumn{2}{|l|}{ Tannins } & + \\
\hline $5 \% \mathrm{FeCl} 3$ & Yellow colour & + \\
\hline \multicolumn{3}{|l|}{ Saponins } \\
\hline Foam test & Foaming & - \\
\hline Froth test & Frothing & - \\
\hline \multicolumn{3}{|l|}{ Flavonoids } \\
\hline $\begin{array}{l}\text { Shinoda test } \\
\text { Phenolics }\end{array}$ & Phenolics & ++ \\
\hline $1 \% \mathrm{FeCl} 3$ & Bluish colour & + \\
\hline \multicolumn{3}{|l|}{ Anthraquinone Glycosides } \\
\hline Borntrager's test & Pink Colour & + \\
\hline \multicolumn{3}{|l|}{ Cardaic Glycosides } \\
\hline Keller killiani Test & Brown ring at junction & + \\
\hline Legal test & Pink colour & + \\
\hline \multicolumn{3}{|l|}{ Terpenoids } \\
\hline Salkowski's test & $\begin{array}{l}\text { Golden yellow ring at } \\
\text { junction }\end{array}$ & ++ \\
\hline \multicolumn{3}{|l|}{ Phytosterols } \\
\hline $\begin{array}{l}\text { Libermann's test } \\
\text { Alkaloids }\end{array}$ & Brown ring at junction & ++ \\
\hline Dragendroff's reagent & Orange ppt & + \\
\hline Mayer's reagent & Cream ppt & - \\
\hline \multicolumn{3}{|l|}{ Proteins } \\
\hline Ninhydrin test & Purple colour & +++ \\
\hline Biuret test & Blue colour & + \\
\hline
\end{tabular}

(+) sign denotes the presence and (-) sign denotes the absence

of acidic and basic compounds present in the extract. The fluorescence is an important phenomenon exhibiting by various chemical constituents present in the plant material and it is an important Pharmacognostic evaluation parameter. The results of phytochemical screening of hydroalcoholic extract of the fruits of Bunium persicum showed the presence of various Phytoconstituents such as flavonoids, terpenoids, carbohydrates tannins etc.

\section{CONCLUSION}

Characteristic macroscopy and microscopy of Bunium persicum (fruit) in this study are suggested to be a benchmark in the selection process of raw materials for the preparation of herbal medicines containing the fruits of Bunium persicum. Pharmacognostic parameters and phytochemical screening were also suggested to be a benchmark for the quality control of the fruits of Bunium persicum.
Table 3: Fluorescence Analysis of the Fruits of Bunium persicum.

\begin{tabular}{|c|c|c|c|}
\hline Treatment & Day Light & UV (254nm) & UV (366nm) \\
\hline Powder as such & Dark brown & Brown & Dark brown \\
\hline $\begin{array}{l}\text { Powder treated } \\
\text { with distilled } \\
\text { water }\end{array}$ & Brown orange & Brown orange & Dark orange \\
\hline $\begin{array}{l}\text { Powder treated } \\
\text { with GAA }\end{array}$ & Brownish orange & Light orange & Light orange \\
\hline $\begin{array}{l}\text { Powder treated } \\
\text { with Conc. } \mathrm{HCl}\end{array}$ & Brown orange & Light orange & Dark orange \\
\hline $\begin{array}{l}\text { Powder treated } \\
\text { with conc. } \mathrm{HCl} \\
\quad+\mathrm{H}_{2} \mathrm{O}\end{array}$ & Yellow orange & Light pink & Light pink \\
\hline $\begin{array}{l}\text { Powder treated } \\
\text { with Pet. ether }\end{array}$ & Brownish grey & Light brown & Dark brown \\
\hline $\begin{array}{l}\text { Powder treated } \\
\text { with } 10 \% \mathrm{NaOH} \text {. }\end{array}$ & Brown yellow & Dark yellow & Brown yellow \\
\hline $\begin{array}{l}\text { Powder treated } \\
\text { with methanol }\end{array}$ & Faded orange & Light pink & Light pink \\
\hline $\begin{array}{l}\text { Powder treated } \\
\text { with ethylacetate }\end{array}$ & Light grey & Light pink & Pink \\
\hline $\begin{array}{l}\text { Powder treated } \\
\text { with conc. } \mathrm{H}_{2} \mathrm{SO}_{4}\end{array}$ & Brown red & Black red & Black red \\
\hline $\begin{array}{l}\text { Powder treated } \\
\text { with conc. } \mathrm{H}_{2} \mathrm{SO}_{4} \\
\quad+\mathrm{H}_{2} \mathrm{O}\end{array}$ & Brown orange & Black orange & Black orange \\
\hline $\begin{array}{l}\text { Powder treated } \\
\text { with picric acid }\end{array}$ & Yellow orange & yellow orange & Dark yellow \\
\hline $\begin{array}{l}\text { Powder treated } \\
\text { with } 5 \% \mathrm{FeCl}_{3}\end{array}$ & Brown orange & Brown orange & Yellow orange \\
\hline $\begin{array}{l}\text { Powder treated } \\
\text { with chloroform }\end{array}$ & Dark orange & Light orange & Dark orange \\
\hline $\begin{array}{l}\text { Powder treated } \\
\text { with } \mathrm{HNO}_{3}\end{array}$ & Brown red & Dark red & Dark red \\
\hline $\begin{array}{c}\text { Powder treated } \\
\text { with } \mathrm{HNO}_{3}+ \\
\mathrm{H}_{2} \mathrm{O}\end{array}$ & Brown orange & Dark orange & Dark orange \\
\hline $\begin{array}{l}\text { Powder treated } \\
\text { with } 5 \% \text { Iodine }\end{array}$ & Brown red & Black red & Dark red \\
\hline
\end{tabular}

\section{ACKNOWLEDGEMENT}

The Authors thank University of Kashmir for providing necessary facilities.

\section{CONFLICT OF INTEREST}

The authors declare that there is no conflict of interest.

\section{ABBREVIATIONS}

UV: Ultraviolet.

\section{REFERENCES}

1. Aminzare M, Amiri E, Abbasi Z, Hassanzadazar H, Hashemi M. Evaluation of in vitro Antioxidant Characteristics of Corn Starch Bioactive Films Impregnated with Bunium persicum and Zataria multiflora Essential Oils. Annu Res Rev Biol. 2017; 15(5):1-9. 
2. Miraj S, Kiani S. Pharmacological activities of Carum carvi L. Pharm Lett. 2016;8(6):135-8.

3. Salehi P, Mohammadi F, Asghari B. Seed essential oil analysis of Bunium persicum by hydrodistillation-headspace solvent microextraction. Chem Nat Compd. 2008;44(1):111-3.

4. Sofi PA, Zeerak NA, Singh P. Kala zeera (Bunium persicum Bioss.) a Kashmirian high value crop. Turk J Biol. 2009;33(3):249-58.

5. Mandegary A, Arab-Nozari M, Ramiar H, Sharififar F. Anticonvulsant activity of the essential oil and methanolic extract of Bunium persicum (Boiss). B Fedtsch J Ethnopharmacol. 2012;140(2):447-51.

6. Judd W, Campbell C, Kellog E. Plant Systematics- a phylogenetic approach. Sinnauer Associates Inc USA. 2002;470-1.

7. Thappa RK, Ghosh S, Agarwal SG, Raina AK, Jamwal PS. Comparative studies on the major volatiles of Kalazira (Bunium persicum seed) of wild and cultivated sources. Food Chemistry. 1991;41(2):129-34.

8. Agah S, Taleb AM, Moeini R, Gorji N, Nikbakht H. Cumin extract for symptom control in patients with irritable bowel syndrome: A case series. Middle East $J$ Dig Dis. 2013;5(4):217-22.

9. Evans WC, Evans D, Trease GE. Trease and Evan's pharmacognosy. $16^{\text {th }}$ ed. Saunders/Elsevier. 2009.
10. Trease GE, Evans WC. Pharmacognosy. International edition. WB. Saunders. 2008;2(3):53844.

11. Chaudhari RD. Herbal drug industry, $1^{\text {st }}$ ed. Eastern Publisher, New Delhi. 1996;498-9.

12. Chase $C R$, Pratt R. Fluorescence of powdered vegetable drugs with reference to development of a system of identification. Journal of Pharmaceutical. 1949;38(6):324-31

13. Pharmacopoeia I. Ministry of health and family welfare. Government of India.1996;2:350.

14. Anonymous. Standardization of Single Drugs of Unani Medicine (Part-II). Central Council for Research in Unani Medicine, New Delhi. 1992.

15. Mukherjee PK. Quality control of herbal drugs: An approach to evaluation of botanicals. New Delhi: Business Horizons Publication. 2002.

16. Kokoski CJ, Kokoski RJ, Slama FJ. Fluorescence of powdered vegetable drugs under ultraviolet radiation. Journal of the American Pharmaceutical Association. 1958;47(10):715-7.

17. Harborne JB. Phytochemical methods in: A guide to modern techniques of plant analysis. $3^{\text {rd }}$ Ed. Chapman and Hall, U.K. ICMR. 1998;56-99.

18. Trease GE, Evans WC. A textbook of Pharmacognosy, London. Bailliare Tindall. 1983;12(193):336

Cite this article: Bhat ZA, Gani R, Dar MA, Dar MA, Rather JY. Pharmacognostic and Phytochemical Characteristics of the Fruits of Bunium persicum (Boiss.)

B. Fedtsch, Growing Wild in Kashmir Valley, India. Int. J. Pharm. Investigation. 2020;10(1):13-6. 